\title{
APRESENTAÇÃO DO DOSSIÊ
}

O dossiê, intitulado Ensino de História, representa uma contribuição ao campo da formação de professores de História. As discussões acerca do Ensino de História têm se ampliando substantivamente o que, sem dúvida, aponta para a importância cada vez mais crescente de uma área que se consolida, pondo em relevo o trabalho daqueles que se dedicam ao fazer docente.

Nesse sentido, trazemos um conjunto de artigos com discussões devidamente contextualizadas que potencializam o debate da formação de professores de História, bem como renovam o nosso fazer e nos fortalece no contexto social a partir de práticas políticas, educativas e sociais muito amplas. São, portanto, produções que dotam de sentido o papel docente.

O presente dossiê aborda desde a prática docente ao uso de linguagens, e, por certo, contribuirá para/com o cotidiano escolar. Isto se constituiu efetivamente em uma das motivações da sua elaboração, ou seja, termos uma produção que também tem a aspiração de chegar aos Professores de Educação básica. Isto certamente, possibilitará que as investigações acadêmicas dialoguem com este universo, favorecendo o processo de atualização dos docentes, nos aspectos teóricos, metodológicos e historiográficos.

Com a proposição da temática, queremos que a edição seja mais um meio de discussões sobre os processos de ensino e aprendizagem de história, onde se analisem os aportes mais recentes e sua contribuição para a formação dos profissionais de história. Notadamente, quando chegamos a segunda década do século XXI assistindo os mais variados acontecimentos no contexto educacional e social, não só pelo número aterrador de conflitos, políticos, sociais e econômicos, como também a imensa quantidade de informações que nos chegam, quer sejam pelos meios de comunicação, quer sejam pelas chamadas redes sociais. Informações rápidas e superficiais.

Dessa maneira, o ensino de História exerce um papel muito importante e fundamental para poder compreender esse cenário e a sociedade da qual fazemos parte. Em vista disso, é evidente que a história, hoje, mais que nunca, requer compreensões minuciosas acerca do contexto em que vivemos.

Em sendo assim, a Revista História, Histórias do programa de pós-graduação em História da Universidade de Brasília - UnB, coloca o atual número à disposição do público, em particular aos leitores especializados, um conjunto de textos que está construído para apoiar a 
reflexão e a renovação no contexto escolar e na formação docente na perspectiva de um ensino de História atualizado e útil que a sociedade está a exigir.

Astrogildo Fernandes Silva Junior e José Josberto Montenegro de Sousa, em seu texto EXPERIÊNCIAS AUSENTES NO ENSINO DE HISTÓRIA: INQUIETANTES PRESSUPOSTOS PARA UMA REORIENTAÇÃO DA VIDA PRÁTICA, nos convidam a compreender como o ensino de história pode contribuir na formação dos jovens estudantes. Os autores apresentam resultados de um projeto que teve como objetivo analisar o potencial das diferentes fontes e das diferentes linguagens da cultura contemporânea no processo de ensino e aprendizagem em história. Para eles, o ensino de história na educação básica necessita reorientar suas práticas, abrangendo outras perspectivas epistemológicas, que possibilitem discutir a diversidade de experiências histórico-culturais negligenciadas e silenciadas.

André Luiz da Silva Cazula e Ana Heloísa Molina em ORIENTAÇÃO TEMPORAL E ENSINO DE HISTÓRLA: PERSPECTIVAS E PRÁTICAS DE PROFESSORES DE HISTÓRIA DA REDE ESTADUAL DE ENSINO. JACAREZINHO-PR. 2015, convidam-nos a pensar sobre as diretrizes para o ensino de História, publicadas pelo estado do Paraná em 2008, e que possuem como principal referência norteadora a teoria da História engendrada por Jörn Rüsen. Com reflexões acerca das perspectivas e práticas docentes em relação às orientações curriculares, o texto é resultado da pesquisa, realizada com dois professores da rede estadual no Ensino Médio, na cidade de Jacarezinho-PR, no ano letivo de 2015, apresentando as apropriações e as estratégias utilizadas na mediação do conhecimento em sala de aula a partir das discussões propostas por Michel De Certeau.

Edson Hely Silva analisa OS ÍNDIOS NA HISTÓRLA E O ENSINO DE HISTÓRIA: AVANÇOS E DESAFIOS. Para ele os povos indígenas no Brasil nos últimos anos conquistaram e ocuparam espaços sociopolíticos, questionando visões eurocêntricas, colonialistas e evolucionistas tratando os povos indígenas como primitivos, desaparecidos ou vítimas impotentes em extinção. $O$ que além de exigir reformulações das teorias explicativas sobre a história e o destino desses povos, vem também exigindo discussões, formulações e efetivação de políticas públicas respondendo as demandas de direitos indígenas sociais específicos.

Jezulino Lúcio Mendes Braga nos apresenta em seu artigo SUJEITOS DE EXPERIÊNCIA: PROFESSORES DE HISTÓRIA NO USO PEDAGÓGICO DO 
MUSEU DE ARTES E OFÍCIOS, parte de sua pesquisa de doutorado na qual investiga a relação dos professores de história com a exposição do Museu de Artes e Ofícios em Belo Horizonte. Apresentando as experiências sensíveis dos docentes no museu o autor discute as escolhas que fazem para ensinar história, nos afirmando que a potencialidade dos museus para o ensino de história está na forma que dispõe os objetos, imagens e legendas e analiso dados sobre as mediações oferecidas pelo museu aos docentes.

Leonardo Nascimento Bourguignon, analisa, em seu artigo REPRESENTAÇÕES DOS NEGROS NOS LIVROS DIDÁTICOS DE HISTÓRIA DO ESPÍRITO SANTO (1964-1997), o papel do livro didático enquanto instrumento de propagação e consolidação de representações, mais especificamente das representações acerca do negro nos livros de história regional. O texto traz como constatação da pesquisa, que, apesar da permanência de uma escrita eurocêntrica, os livros produzidos por autores capixabas apresentaram, em diversos momentos, o negro como agente ativo na história local, mesmo antes da existência de uma legislação que assim os exigisse, e a frente inclusive de uma tendência nacional.

Magno Francisco de Jesus Santos em ENSINO DE HISTÓRLA, ESPAÇOS E CULTURA POLÍTICA BANDEIRANTE: JOSÉ SCARAMELI E A ESCRITA DE LIVROS ESCOLARES DE HISTÓRIA PARA CRIANÇAS, nos traz a discussão sobre a escrita da história para crianças no Brasil, a partir da experiência de Scarameli. Intelectual defensor dos ideais do movimento escolanovista, entre 1926 e 1934, Scarameli produziu um número significativo de livros escolares de História e de Moral e Cívica. Trata-se, pois, de uma discussão como estes livros expressaram as estratégias de difusão de uma cultura política bandeirante e a construção de representações acerca dos estados brasileiros com um protagonismo paulista.

Marcella Albaine Farias da Costa O QUE NARRAM LICENCIANDOS DE HISTÓRLA SOBRE O IMPACTO DA TECNOLOGLA EM SUA FORMAÇÃO INICLAL?. A autora nos revela de que forma professores de História em formação inicial - alunos das turmas de Didática Especial de História e Prática de Ensino de História da UFRJ e participantes do Programa Institucional de Bolsas de Iniciação à Docência (PIBID) - significam sua trajetória profissional no que tange à temática da tecnologia. A experiência, foi pautada no olhar (auto) biográfico e utilizou-se da plataforma do Museu da Pessoa enquanto possibilidade metodológica.

Talia Meschiany e Verónica Hendel enveredam pelos caminhos do ENSINAR E 
APRENDER HISTÓRIA: REFLEXÕES EM TORNO DE EXPERIÊNCIAS DE FORMAÇÃO DOCENTE CONTÍNUA EM MEIOS VIRTUAIS NA PROVÍNCLA DE BUENOS AIRES. As autoras nos apresentam reflexões preliminares sobre um conjunto de práticas e representações do fazer de professores sobre o ensino da história, parte do Departamento de Educação Continuada (DFC) da Direcção-Geral da Educação e Cultura da província de Buenos Aires (DGCyE) durante os anos de 2015 e 2016. No texto analisam como a formação de professores em exercício através de Ambientes Virtuais de Aprendizagem (EVA) promovem e fortalecem as boas práticas de ensino.

Vitória Azevedo Fonseca, em CINEMA E ENSINO DE HISTÓRIA ENTRE DEBATES E PRÁTICAS, apresenta a partir de um rico debate sobre como usar filmes em salas de aula, especificamente no ensino de história, a experiência de exibição do mesmo filme (Sonhos Tropicais, André Sturn, 2002) para diferentes turmas do $9^{\circ}$ ano do Ensino Fundamental, adotando procedimentos preparatórios diferenciados a fim de discutir e defender a importância de, além da alfabetização da linguagem cinematográfica refletir também sobre o desenvolvimento da compreensão dos estudantes dos debates e diálogos "historiográficos" estabelecidos pela narrativa audiovisual para compreensão das intertextualidades presentes nos filmes.

Por fim, Wilian Junior Bonete, em seu texto ALUNOS DA EJA FALAM SOBRE A HISTÓRLA ENSINADA: RELAÇÕES ENTRE HISTÓRLA E VIDA PRÁTICA, busca identificar e analisar o pensamento de um grupo de 66 alunos da Educação de Jovens e Adultos (EJA), de uma escola Estadual no Paraná, sobre o conhecimento histórico e suas relações com a vida prática. Para tanto, estabelece diálogos com a concepção de consciência histórica, tal como proposto por Jörn Rüsen, bem como os pressupostos que embasam o campo investigativo da Didática da História.

Este dossiê discute, a partir de diversos olhares, as dimensões políticas e didáticas que atravessam nossas concepções de pensar a formação de professores. A qualidade dos textos resulta da soma de esforços de docentes de várias localidades do Brasil para produzirem um primeiro número da História, História dedicado ao Ensino de História, permitindo que, pela primeira vez, professores pesquisadores da área possam intercambiar textos, experiências e estratégias de ensino e aprendizagem de História. Uma ótima leitura!

\section{Prof. Dr. Carlos Augusto Lima Ferreira}

Brasil - Universidade Estadual de Feira de Santana - UEFS

e-mail: calfferreira@gmail.com 